\title{
Ignition of Droplets in a Laminar Convective Environment
}

\author{
Rainer Stauch and Ulrich Maas \\ Institut für Technische Thermodynamik, Universität Karlsruhe, \\ Kaiserstraße 12, D-76128 Karlsruhe, Germany \\ umaas@itt.mach.uni-karlsruhe.de
}

Summary. Numerical simulations of the ignition process of methanol and nheptane droplets in a laminar convective environment are performed using detailed reaction mechanisms and detailed transport models. The ignition delay time of a single droplet is found to decrease with increasing velocity of the convective gas flow. This decrease is attributed to the steepening of the spatial gradients of the profiles of physical variables, like species mass fractions or temperature. This steepening is originated by a stronger gas flow and leads to a speed-up of the physical transport processes. A downstream movement of the local ignition point with increasing flow velocity is observed. For higher flow velocities an ignition in the wake of the droplet followed by an upstream flame propagation is found. After ignition an envelope flame is formed. The structure of this envelope flame is studied.

\section{Introduction}

For the understanding of spray combustion a detailed knowledge of the processes associated with droplet ignition and combustion is required. Especially a detailed understanding of the basic physical and chemical processes, like vaporization, transport and chemical kinetics, and their interaction is of interest. The ignition or combustion process of single droplets in a quiescent atmosphere has been investigated in detail both experimentally and numerically for different fuels, e.g. methanol [CCD90, CYD92, Sta92] or n-heptane [HK90, TTN93, NKKN94, TKS ${ }^{+}$95, $\mathrm{TBE}^{+}$96, JA96, SDM98, CD99, MDN99, $\mathrm{SMC}^{+} 00, \mathrm{MMKE}$ 5, $\mathrm{CMBF}^{+}$05, SLM06]. In all technical applications fuel droplets are exposed to a convective environment and to accelerating or decelerating forces. Therefore the influence of a convective gas flow and a relative acceleration of droplet and gas phase on the ignition and combustion process of fuel droplets has to be investigated in order to achieve a more reliable modeling of spray ignition and combustion [TS90, DASN96, HC97, WYHW97, SDM98, YYWW00, $\mathrm{AMG}^{+}$01]. Ignition delay times have been determined experimentally by Whang et al. [WYHW97] 
and Yang et al. [YYWW00] for n-heptane, n-hexadecane and i-octane and numerically by Aouina et al. $\left[\mathrm{AMG}^{+} 01\right]$ for methanol and LOX (liquid oxygen) droplets. The influence of gravitational acceleration on the ignition behavior of droplets is discussed in [FO68, $\left.\mathrm{TKS}^{+} 95, \mathrm{VCC}^{+} 96, \mathrm{HC}^{2}, \mathrm{SMC}^{+} 00, \mathrm{CGS}^{+} 00\right]$.

In this study the ignition process of single methanol and n-heptane droplets in a convective air environment is investigated. Detailed models for the phase transition, the transport processes and the chemical kinetics are applied.

\section{Numerical model}

To investigate the interaction of the physical and chemical processes, detailed numerical simulations are an efficient tool, because they allow to evaluate the contributions of chemical reactions, flow, and molecular transport. The presented model describes a spherical fuel droplet surrounded by an ambient gas phase. The droplet is exposed to a laminar convective gas flow. This system is analogous to a moving droplet in a gas environment with a velocity which is constant in time. The studied configuration is assumed to have rotational symmetry, and the resulting computational domain is shown in Fig. 1.

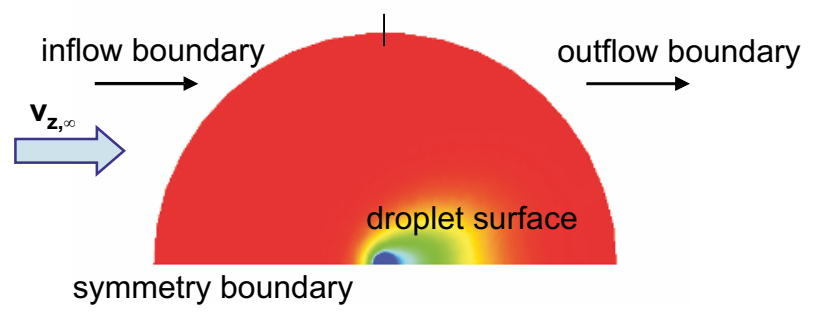

Fig. 1. Computational domain and boundaries

The governing set of equations is given by the compressible Navier-Stokes equations for reacting flows [HC49, BSL60, WMD01]. Assuming a cylindrical symmetry, the results are independent of the azimuthal coordinate $\phi$ (Note, that the axisof symmetry, i. e. the $z$-axis, is parallel to the direction of the axisymmetric flow.). Hence, the number of independent variables is reduced to three, namely the time $t$, the axial coordinate $z$, and the radial coordinate $r$.

$$
\underbrace{f=f(x, y, z, t)}_{3 D} \rightarrow \underbrace{f=f(r, z, t)}_{2 D}
$$


The resulting equation system reads:

$$
\begin{aligned}
\frac{\partial \rho}{\partial t}+\frac{1}{r} \frac{\partial}{\partial r}\left(\rho r v_{r}\right)+\frac{\partial}{\partial z}\left(\rho v_{z}\right) & =0 \\
\frac{\partial \rho_{i}}{\partial t}+\frac{1}{r} \frac{\partial}{\partial r}\left(\rho_{i} r v_{r}\right)+\frac{\partial}{\partial z}\left(\rho_{i} v_{z}\right)+\frac{1}{r} \frac{\partial}{\partial r}\left(r\left(j_{i}\right)_{r}\right)+\frac{\partial}{\partial z}\left(\left(j_{i}\right)_{z}\right) & =M_{i} \dot{\omega}_{i} \\
\frac{\partial\left(\rho v_{r}\right)}{\partial t}+\frac{1}{r} \frac{\partial}{\partial r}\left(\rho r v_{r} v_{r}\right)+\frac{\partial}{\partial z}\left(\rho v_{r} v_{z}\right)+\frac{\partial p}{\partial r} & \\
+\frac{1}{r} \frac{\partial}{\partial r}\left(r \Pi_{r r}\right)-\frac{\Pi_{\phi \phi}}{r}+\frac{\partial}{\partial z}\left(\Pi_{r z}\right) & =\rho g_{r} \\
\frac{\partial\left(\rho v_{z}\right)}{\partial t}+\frac{\partial}{\partial r}\left(\rho r v_{r} v_{z}\right)+\frac{\partial}{\partial z}\left(\rho v_{z} v_{z}\right)+\frac{\partial p}{\partial z} & \\
+\frac{1}{r} \frac{\partial}{\partial r}\left(r \Pi_{r z}\right)+\frac{\partial}{\partial z}\left(\Pi_{z z}\right) & =\rho g_{z} \\
\frac{\partial \rho u}{\partial t}+\frac{1}{r} \frac{\partial}{\partial r}\left(\rho u r v_{r}\right)+\frac{\partial}{\partial z}\left(\rho u v_{z}\right)+\frac{1}{r} \frac{\partial}{\partial r}\left(r\left(j_{q}\right)_{r}\right)+\frac{\partial}{\partial z}\left(\left(j_{q}\right)_{z}\right) & \\
+p\left(\frac{1}{r} \frac{\partial}{\partial r}\left(r v_{r}\right)+\frac{\partial v_{z}}{\partial z}\right) & \\
+\Pi_{r r} \frac{\partial v_{r}}{\partial r}+\Pi_{\phi \phi} \frac{1}{r} \frac{v_{r}}{r}+\Pi_{z z} \frac{\partial v_{z}}{\partial z}+\Pi_{r z}\left(\frac{\partial v_{r}}{\partial z}+\frac{\partial v_{z}}{\partial r}\right) & =0 .
\end{aligned}
$$

The components of the stress tensor $\Pi$ read [BSL60]:

$$
\begin{aligned}
& \Pi_{r r}=-\mu\left(2 \frac{\partial v_{r}}{\partial r}-\frac{2}{3}\left(\frac{1}{r} \frac{\partial}{\partial r}\left(r v_{r}\right)+\frac{\partial v_{z}}{\partial z}\right)\right) \\
& \Pi_{\phi \phi}=-\mu\left(2 \frac{v_{r}}{r}-\frac{2}{3}\left(\frac{1}{r} \frac{\partial}{\partial r}\left(r v_{r}\right)+\frac{\partial v_{z}}{\partial z}\right)\right) \\
& \Pi_{z z}=-\mu\left(2 \frac{\partial v_{z}}{z}-\frac{2}{3}\left(\frac{1}{r} \frac{\partial}{\partial r}\left(r v_{r}\right)+\frac{\partial v_{z}}{\partial z}\right)\right) \\
& \Pi_{r z}=-\mu\left(\frac{\partial v_{r}}{\partial z}+\frac{\partial v_{z}}{\partial r}\right)
\end{aligned}
$$

where $\rho$ denotes the density, $u$ the specific internal energy, $\rho_{i}$ the partial densities, $p$ the pressure, $j_{i}$ the diffusion flux density of species $i, \omega_{i}$ the molar rate of formation of species $i, M_{i}$ the molar mass of species $i$, and $j_{q}$ the heat flux density. $v_{r}$ and $v_{z}$ are the velocity components in radial and axial direction, respectively, and $g_{r}$ and $g_{z}$ the components of the gravitational acceleration.

The system of the governing equations has to be completed by an equation of state for both the gas and the liquid phase. The gas phase is assumed to be ideal. In the liquid phase the Hankinson-Brobst-Thomson technique is used to model the temperature dependence of the liquid density [HT79, RPP89].

The chemical kinetics of methanol is modeled by a detailed reaction mechanism of Chevalier and Warnatz [WMD01], consisting of 23 chemical species 
and 166 elementary reactions, and the chemical kinetics of n-heptane is modeled by a detailed mechanism by Golovitchev [Gol04] with 56 species and 570 reactions. The transport processes are also modeled in detail. Fourier's law is used to determine the conductive heat fluxes. For the determination of the diffusion flux density the approximation of Curtiss and Hirschfelder [HCB64] is used. Details of the implementation of the transport model for the gas phase can be found in [MW88]. Convection inside the droplet is neglected. The physical properties of the liquid phase and of the phase transition are determined by the following correlations taken from Reid et al. [RPP89]: The correlation of Latini and Baroncini is used to calculate the heat conductivities [LB83], the approximation of Rowlinson and Bondi is applied to determine the specific heat capacities of the liquid phase [Row69]. The vapor pressure is calculated following the Wagner equation [WEP76], and the correlation of Riedel and Watson is used to calculate the enthalpy of vaporization [Rie54, TS66, VK67].

At the inflow boundary (cf. Fig. 1) Dirichlet conditions are used

$$
\rho=\rho_{\infty}, \quad v_{r}=0, \quad v_{z}=v_{z, \infty}, \quad w_{i}=w_{i, \infty}, \quad T=T_{\infty},
$$

and at the outflow boundary the conditions read:

$$
\frac{\partial p}{\partial z}=0, \frac{\partial v_{r}}{\partial z}=0, \frac{\partial v_{z}}{\partial z}=0, \frac{\partial w_{i}}{\partial z}=0, \frac{\partial T}{\partial z}=0
$$

For the axis of symmetry we obtain

$$
r=0: \quad \frac{\partial \rho}{\partial r}=0, \quad v_{r}=0, \frac{\partial v_{z}}{\partial r}=0, \frac{\partial w_{i}}{\partial r}=0, \frac{\partial T}{\partial r}=0
$$

A vaporization model accounts for the coupling of the liquid phase and the gas phase. The assumption of a local phase equilibrium is modeled by interface equations.

$$
\begin{aligned}
\phi_{\text {vap }} & =\frac{-\sum_{j_{\text {vap }}} j_{j}^{g}-\sum_{j_{\text {vap }}} w_{j} \sum_{i} R_{i}+\sum_{j_{\text {vap }}} R_{j}}{\sum_{j_{\text {vap }}} \frac{p_{j} M_{j}}{p M}-1} \\
0 & =\rho \cdot v_{n}-\phi_{\mathrm{vap}}-\sum_{i} R_{i} \\
0 & =\phi_{\mathrm{vap}}\left(w_{i}-\epsilon_{i}\right)+j_{i}+w_{i} \sum_{j} R_{j}-R_{i} \\
0 & =\sum_{i} \epsilon_{i} \cdot \phi_{\mathrm{vap}} \cdot \Delta h_{\mathrm{vap}, i}+j_{q, c}^{g}-j_{q, c}^{l}+\sum_{i} R_{i}\left(h_{i}^{g}-h_{i}^{l}\right)
\end{aligned}
$$

$\phi_{\text {vap }}$ denotes the vaporization rate, $w_{i}$ the species mass fraction $j_{\text {vap }}$ the index of the vaporizing species, $p_{j}$ the partial pressure of species $j, \bar{M}$ the mean molar mass, $v_{n}$ the velocity normal to the surface, $\epsilon_{i}=\dot{m}_{i} / \dot{m}$ the fraction of vaporizing mass, $j_{i}$ the diffusion flux density of species $i$ (gas phase), $\Delta h_{\mathrm{vap}, i}$ 
the enthalpy of vaporization of species $i, j_{q, c}$ the conductive heat flux density and $h_{i}$ the enthalpy of species $i . R_{i}$ is the surface reaction rate of species $i$, which is 0 for the calculations presented here and has only been included in the model for generality (e.g. to allow modeling of combustion of solid particles with surface oxidation). More details can be found in [SLM06].

The governing equations are solved in a fully coupled way by the method of lines using finite difference techniques. The equations are transformed into boundary-fitted curvilinear coordinates generated by TOMCAT [TTM77]. The flux vector splitting upwind scheme of Steger and Warming [SW81] is applied to calculate the inviscid fluxes. The viscous fluxes are discretized using second order central differences in chain rule conservation law form [RMW93b]. The time integration of the resulting differential-algebraic equation system is realized by the linearly implicit extrapolation method LimEx [DHZ87]. Details on the numerical solution can be found in [RMW93b, RMW93a, $\left.\mathrm{AMG}^{+} 01\right]$.

\section{Results and Discussion}

Based on the model presented above the auto-ignition of single methanol and n-heptane droplets in a laminar convective environment has been simulated for varying conditions of ambient gas temperature and flow velocities. The surrounding gas phase consists of air in all cases. The ambient pressure is $p=7$ bar. The ambient gas temperature varies between $T=1000 \mathrm{~K}$ and $T=1500 \mathrm{~K}$.

For the auto-ignition of a fuel droplet it is important to know how the ignition process is influenced by the gas flow. In contrast to the microgravity case the flame zone does not have a spherical shape anymore [HC97, WYHW97, $\left.\mathrm{AMG}^{+} 01\right]$. Furthermore, the flow has an important impact on the ignition process. This can be seen for a methanol droplet in Fig. 2. The flame position is defined as the location of maximal $\mathrm{OH}$-concentration. The gas flows from the left to the right. With increasing flow velocity, the shape of the flame deviates more and more from a spherical shape. The extension of the flame in $\mathrm{x}$-direction increases with increasing gas velocity. At the same time the extension in $y$-direction becomes smaller. Furthermore, it is remarkable that the maximal $\mathrm{OH}$-concentration increases with increasing flow velocity. This can be attributed to faster mixing of the fuel with the oxidizer. The maximum $\mathrm{OH}$-concentration is located at the stagnation point upstream of the droplet. On the other hand the maximum OH-concentration downstream of the droplet decreases with increasing flow velocity. As can be seen in Fig. 2 the droplet is surrounded by a non-premixed flame.

In Fig. 3 the dependence of the ignition delay time for a methanol droplet on the inflow velocity in terms of the Reynolds number is shown, where the Reynolds number is defined as: $\operatorname{Re}=\rho_{\text {air }} v_{\text {air }} \cdot d_{D} / \mu_{\text {air }}$ with $d_{D}$ as the droplet diameter, and $\rho_{\text {air }}, v_{\text {air }}$, and $\mu_{\text {air }}$ as the density, the velocity, and the viscosity of the ambient air, respectively. A significant decrease of the ignition delay 

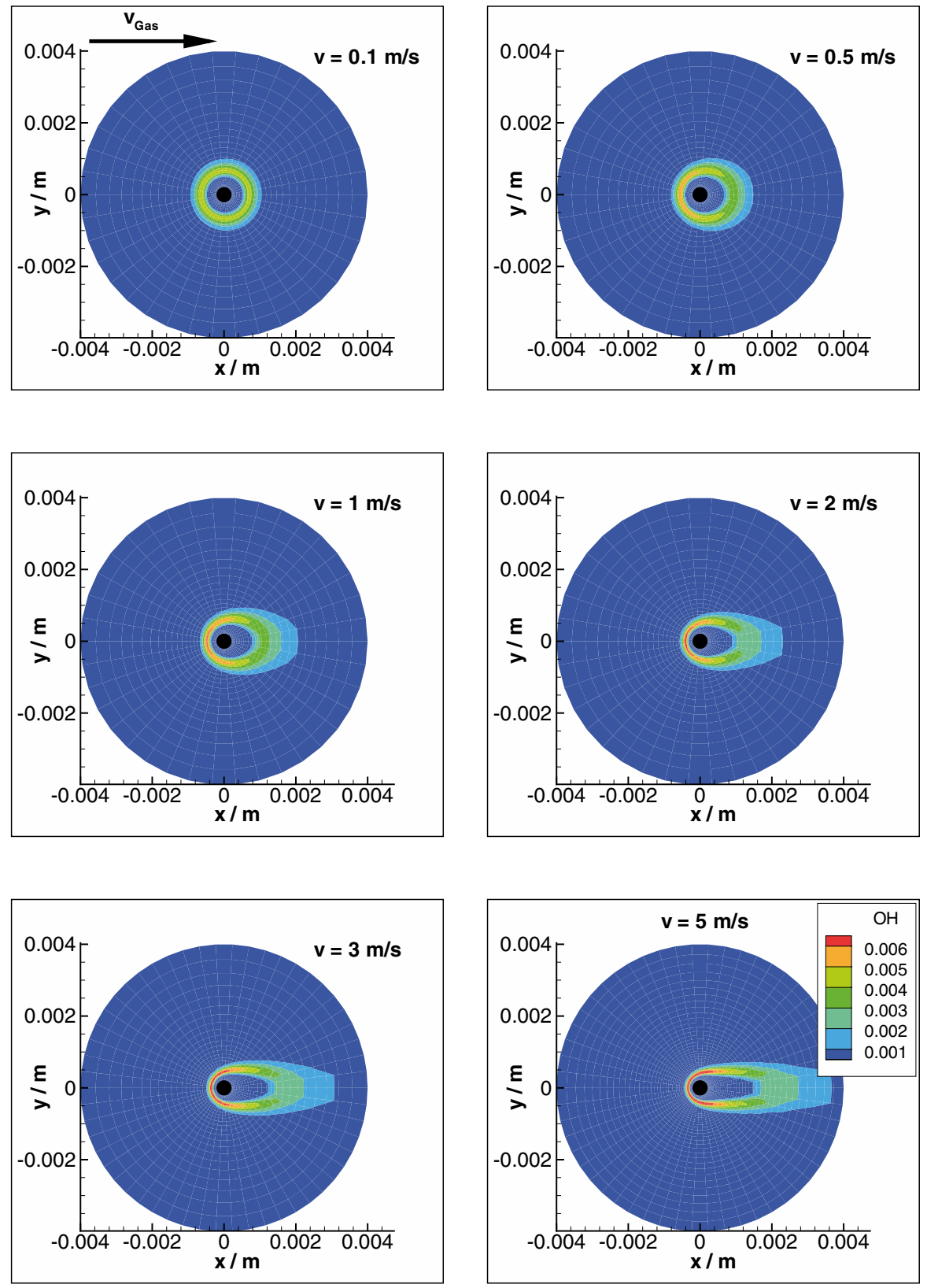

Fig. 2. Change of the flame structure with increasing gas velocity (methanol, $T_{g}=1400 \mathrm{~K}, p=7 \mathrm{bar}, r_{D}(0)=200 \mu \mathrm{m}, t=9 \mathrm{~ms}$, flow from the left to the right) 


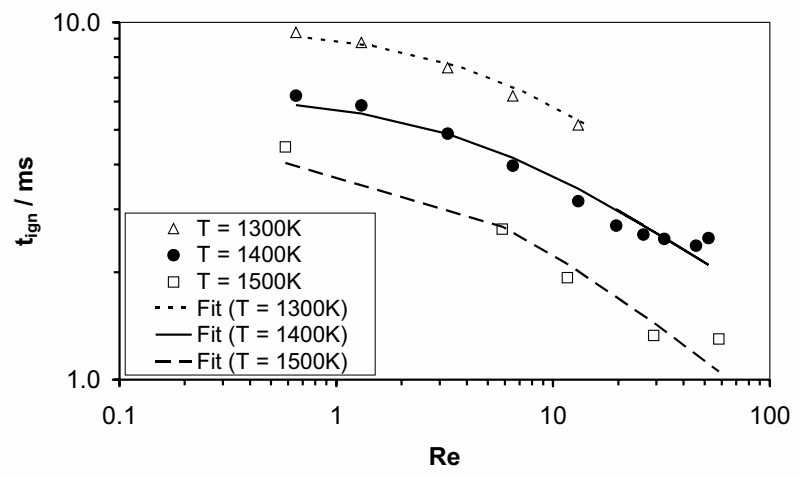

Fig. 3. Dependence of the ignition delay time for a methanol droplet on the Reynolds number $\left(p=7\right.$ bar, $\left.r_{D}(0)=200 \mu \mathrm{m}\right)$

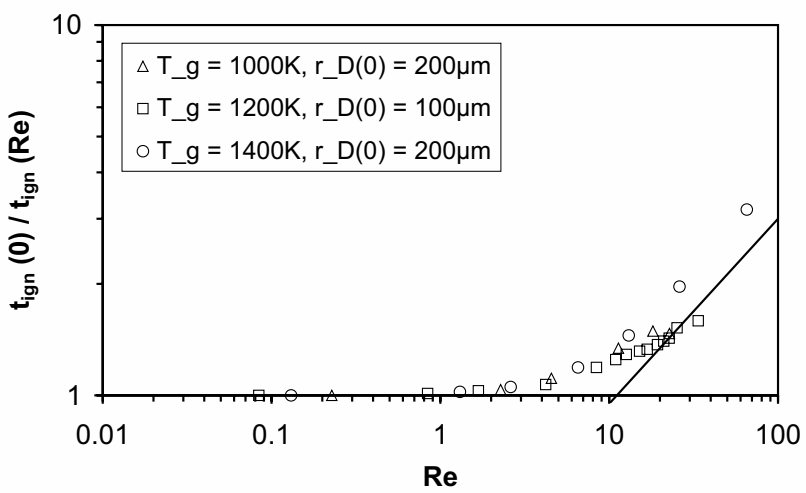

Fig. 4. Dependence of the inverse normalized ignition delay time of a heptane droplet on the Reynolds number $(p=7$ bar)

time with increasing flow velocity can be observed. As one can see a variation of the flow velocity by an order of magnitude has a comparable effect on the ignition delay time like a variation of the gas temperature by $\pm 100 \mathrm{~K}$.

Figure 4 shows the dependence of the normalized reciprocal ignition delay times for a heptane droplet on the flow velocity for three different gas temperatures. Again an increase of the inverse ignition delay time with increasing Reynolds number is observed. The normalized reciprocal ignition delay times for $T_{g}=1200 \mathrm{~K}$ show a smaller slope, because a radius of $r_{D}(0)=100 \mu \mathrm{m}$ has been chosen and the Damköhler number is smaller for smaller droplets. In general the ignition delay times of heptane droplets depend less on the gas flow, which can be attributed to a smaller Damköhler number in this case. 
Even if the ignition starts downstream of the droplet, the flame zone propagates upstream and forms an envelope flame. This behavior is important in technical applications, because in most sprays ignition is initiated downstream of the droplets [WLY97].

Figure 5 shows this behavior for the ignition of a methanol droplet. The left figure shows the temperature field at the end of the ignition. The arrow indicates the subsequent propagation of the flame zone, which is shown in the two other figures. The right figure shows the flame when it is located close to the droplet. After that the flame propagates further upstream, and forms an envelope flame.

The ignition location is governed by the flow velocity. The local point of ignition moves gradually from the upstream region of the droplet at lower velocities to the wake of the droplet for increasing flow velocities. This is illustrated in Fig. 6, in which the different points of ignition depending on the gas flow velocity are shown for the example of a methanol droplet. In all investigated cases up to a flow velocity of $5 \mathrm{~m} / \mathrm{s}$ after ignition the formation of an envelope flame can be observed. Heptane shows a similar behavior as can be seen in Fig. 7. For low velocities the ignition occurs upstream, too, and moves downstream with increasing gas velocity. Nevertheless, the quantitative behavior is different due to the different chemical time scales

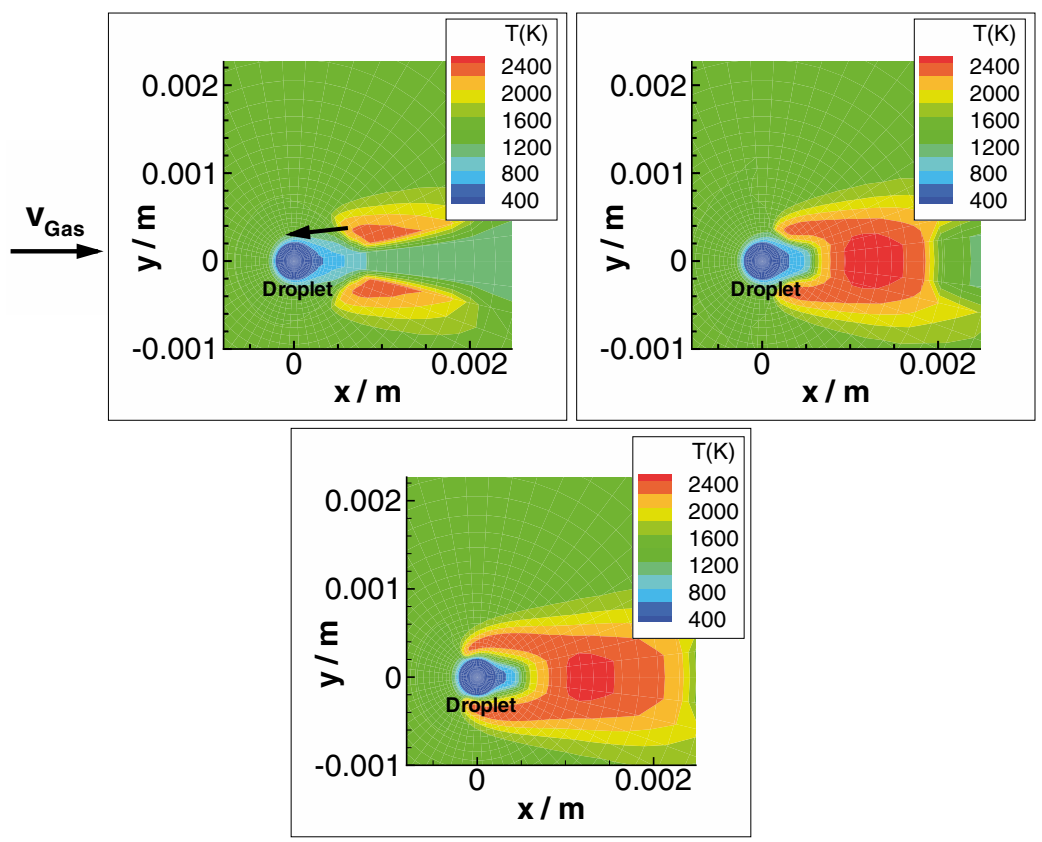

Fig. 5. Upstream propagation of the reaction zone after an ignition downstream of the droplet (methanol, $T_{g}=1400 \mathrm{~K}, p=7 \mathrm{bar}, r_{D}(0)=200 \mu \mathrm{m}, v=3 \mathrm{~m} / \mathrm{s}$, left: $t_{1}=2.80 \mathrm{~ms}$, right: $t_{2}=2.92 \mathrm{~ms}$, bottom: $\left.t_{3}=3.04 \mathrm{~ms}\right)$ 


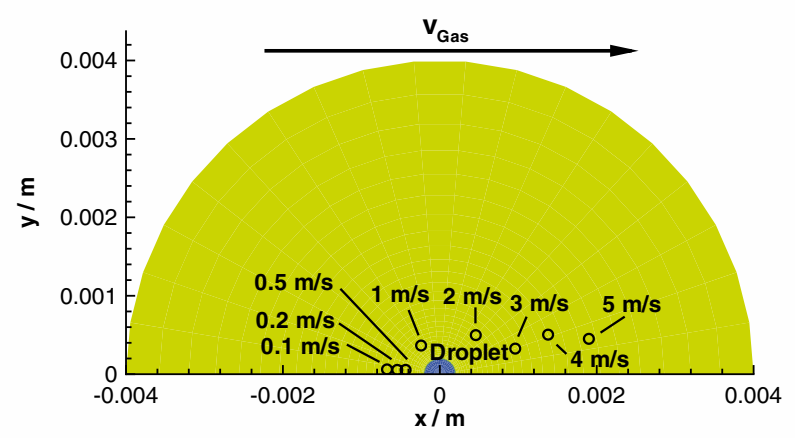

Fig. 6. Dependence of the location of the ignition point on convective velocity of gas flow (methanol, $T=1400 \mathrm{~K}, p=7 \mathrm{bar}, r_{D}(0)=200 \mu \mathrm{m}$ )

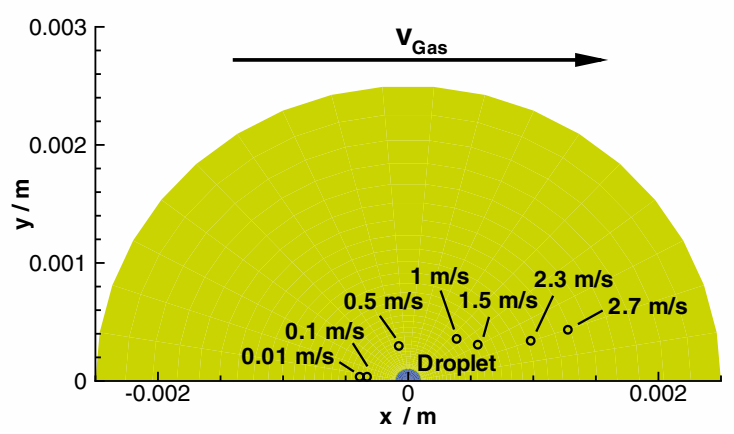

Fig. 7. Location of the ignition for different gas velocities (n-heptane, $T_{g}=1200 \mathrm{~K}$, $p=7$ bar, $\left.r_{D}(0)=100 \mu \mathrm{m}\right)$

of the two fuels. These findings show resemblance with the observations of Whang et al. [WYHW97], who observed the formation of an envelope flame in all studied cases of n-heptane and n-hexadecane droplets.

\section{Conclusions}

The auto-ignition process of methanol and n-heptane droplets in a convective environment is investigated numerically. The simulations are performed by the developed tool FLAME2D by solving the governing equations of the gas and the liquid phase in a fully coupled way including a detailed vaporization model, a detailed transport model, and a detailed reaction mechanism.

The influence of a gas flow on the ignition process is investigated. The ignition delay time decreases with an increasing velocity of the gas flow velocity for different ambient gas temperatures. The ignition process as a whole is 
quite remarkably affected by a modified gas flow velocity. With an increasing flow velocity the location of ignition is moving from upstream the droplet, around the droplet to the wake of the droplet.

To investigate the upstream flame propagation and the characteristics of the envelope flame in more detail for conditions of practical relevance, simulations have to be performed with lower gas flow velocities at lower ambient temperatures where the chemical kinetics plays a major role for the time scales of the ignition and combustion process of a droplet. This involves a considerable increase of computing time. Therefore, the further improvement of the numerical solution of the governing equations with respect to a speed-up of the solution procedure is subject of future work.

\section{Acknowledgements}

The simulations were performed on the national super computer NEC SX-8 at the High Performance Computing Center Stuttgart (HLRS) under the grant number flame2D/12792. The authors acknowledge the support of Dr. Peter Lammers from the High Performance Computing Center Stuttgart (HLRS) in optimizing the code for simulations on the NEC SX-8.

\section{References}

$\left[\mathrm{AMG}^{+} 01\right]$ Y. Aouina, U. Maas, E. Gutheil, U. Riedel, and J. Warnatz. Mathematical modeling of droplet heating, vaporization and ignition including detailed chemistry. Combustion Science and Technology, 173:1-23, 2001.

[BSL60] R.B. Bird, W.E. Steward, and E.N. Lightfoot. Transport Phenomena. John Wiley \& Sons, New York, Chichester, Brisbane, Toronto, Singapore, 1960.

[CCD90] S.Y. Cho, M.Y. Choi, and F.L. Dryer. Extinction of a free methanol droplet in microgravity. Proceedings of the Combustion Institute, 23:1611-1617, 1990.

[CD99] S.Y. Cho and F.L. Dryer. A numerical study of the unsteady burning behaviour of n-heptane droplets. Combustion Theory and Modelling, 3:267-280, 1999.

$\left[\mathrm{CGS}^{+} 00\right]$ C. Chauveau, I. Gökalp, D. Segawa, T. Kadota, and H. Enomoto. Effects of reduced gravity on methanol droplet combustion at high pressures. Proceedings of the Combustion Institute, 28:1071-1077, 2000.

$\left[\mathrm{CMBF}^{+} 05\right]$ A. Cuoci, M. Mehl, G. Buzzi-Ferraris, T. Faravelli, D. Manca, and E. Ranzi. Autoignition and burning rates of fuel droplets under microgravity. Combustion and Flame, (143):211-226, 2005.

[CYD92] S.Y. Cho, R.A. Yetter, and F.L. Dryer. A computer model for one dimensional mass and energy transport in and around chemically reacting particles, including complex gas-phase chemistry, multi-component molecular diffusion, surface evaporation, and heterogeneous reaction. Journal of Computational Physics, 102:160-179, 1992. 
[DASN96] H.A. Dwyer, I. Aharon, B.D. Shaw, and H. Niazmand. Surface tension influences on methanol droplet vaporization in the presence of water. Proceedings of the Combustion Institute, 26:1613-1619, 1996.

[DHZ87] P. Deuflhard, E. Hairer, and J. Zugck. One-step and extrapolation methods for differential-algebraic systems. Numerische Mathematik, 51:501-516, 1987.

[FO68] G.M. Faeth and D.R. Olson. The ignition of hydrocarbon fuel droplets in air. SAE Transactions, pages 1793-1802, 1968.

[Gol04] V. Golovitchev. http://www.tfd.chalmers.se / valeri/MECH.html, 2004.

[HC49] J.O. Hirschfelder and C.F. Curtiss. Theory of propagation of flames. part i: General equations. Proceedings of the Combustion Institute, 3:121-127, 1949.

[HC97] L.-W. Huang and C.-H. Chen. Droplet ignition in a high-temperature convective environment. Combustion and Flame, 109:145-162, 1997.

[HCB64] J.O. Hirschfelder, C.F. Curtiss, and R.B. Bird. Molecular Theory of Gases and Liquids. John Wiley \& Sons, New York, 1964.

[HK90] H. Hara and S. Kumagai. Experimental investigation of free droplet combustion under microgravity. Proceedings of the Combustion Institute, 23:1605-1610, 1990.

[HT79] R.W. Hankinson and G.H. Thomson. A new correlation for saturated densities of liquids and their mixtures. AIChE Journal, 25:653-663, 1979.

[JA96] G.S. Jackson and C.T. Avedisian. Modeling of spherically symmetric droplet flames including complex chemistry: Effect of water addition on n-heptane droplet combustion. Combustion Science and Technology, 115:125-149, 1996.

[LB83] G. Latini and C. Baroncini. Effect of temperature and pressure on thermal conductivity of organic liquids. High Temperatures - High Pressures, 15:407-411, 1983.

[MDN99] A.J. Marchese, F.L. Dryer, and V. Nayagam. Numerical modeling of isolated n-alkane droplet flames: Initial comparisons with ground and space-based microgravity experiments. Combustion and Flame, 116:432-459, 1999.

[MMKE05] O. Moriue, M. Mikami, K. Kojima, and C. Eigenbrod. Numerical simulations of the ignition of n-heptane droplets in the transition diameter range from heterogeneous to homogeneous ignition. Proceedings of the Combustion Institute, 30:1973-1980, 2005.

[MW88] U. Maas and J. Warnatz. Ignition processes in hydrogen-oxygen mixtures. Combustion and Flame, 74:53-69, 1988.

[NKKN94] R. Nakanishi, H. Kobayashi, S. Kato, and T. Niioka. Ignition experiment of a fuel droplet in high-pressure high-temperature ambient. Proceedings of the Combustion Institute, 25:447-453, 1994.

[Rie54] L. Riedel. Kritischer koeffizient, dichte des gesättigten dampfes und verdampfungswärme. Chemie Ingenieur Technik, 26:679-683, 1954.

[RMW93a] U. Riedel, U. Maas, and J. Warnatz. Detailed numerical modeling of chemical and thermal nonequilibrium in hypersonic flows. Impact of Computing in Science and Engineering, 5:20-52, 1993.

[RMW93b] U. Riedel, U. Maas, and J. Warnatz. Simulation of nonequilibrium hypersonic flows. Computers and Fluids, 22:285-294, 1993. 
[Row69] J.S. Rowlinson. Liquids and Liquid Mixtures. Butterworths, 2 edition, 1969.

[RPP89] R.C. Reid, J.M. Prausnitz, and B.E. Poling. The Properties of Gases and Liquids. McGraw-Hill, 4 edition, 1989.

[SDM98] P. Stapf, H.A. Dwyer, and R.R. Maly. A group combustion model for treating reactive sprays in i.c. engines. Proceedings of the Combustion Institute, 27:1857-1864, 1998.

[SLM06] R. Stauch, S. Lipp, and U. Maas. Detailed numerical simulations of the auto-ignition of single n-heptane droplets in air. Combustion and Flame, 145:533-542, 2006.

$\left[\mathrm{SMC}^{+} 00\right]$ S. Schnaubelt, O. Moriue, T. Coordes, C. Eigenbrod, and H.J. Rath. Detailed numerical simulations of the multistage self-ignition process of n-heptane isolated droplets and their verification by comparison with microgravity experiments. Proceedings of the Combustion Institute, 28:953-960, 2000.

[Sta92] P. Stapf. Modellierung der Tröpfchenverbrennung unter Einschluß detaillierter chemischer Reaktion. PhD thesis, Universität Stuttgart, 1992.

[SW81] J.L. Steger and R.F. Warming. Flux vector splitting of the inviscid gasdynamic equations with application to finite-difference methods. Journal of Computational Physics, 40:263-293, 1981.

$\left[\mathrm{TBE}^{+} 96\right]$ M. Tanabe, T. Bolik, C. Eigenbrod, H.J. Rath, J. Sato, and M. Kono. Spontaneous ignition of liquid droplets from a view of non-homogeneous mixture formation and transient chemical reactions. Proceedings of the Combustion Institute, 26:1637-1643, 1996.

$\left[\mathrm{TKS}^{+} 95\right]$ M. Tanabe, M. Kono, J. Sato, J. Koenig, C. Eigenbrod, F. Dinkelacker, and H.J. Rath. Two stage ignition of n-heptane isolated droplets. Combustion Science and Technology, 108:103-119, 1995.

[TS66] R.E. Thek and L.I. Stiel. A new reduced vapor pressure equation. AIChE Journal, 12:599-603, 1966.

[TS90] J.S. Tsai and A.M. Sterling. The combustion of linear droplet arrays. Proceedings of the Combustion Institute, 23:1405-1411, 1990.

[TTM77] J.F. Thompson, F.C. Thames, and C.W. Mastin. Tomcat - a code for numerical generation of boundary-fitted curviliniear coordinate systems on fields containing any number of arbitrary two-dimensional bodies. Journal of Computational Physics, 24:274-302, 1977.

[TTN93] M. Takei, T. Tsukamoto, and T. Niioka. Ignition of blended-fuel droplet in high-temperature atmosphere. Combustion and Flame, 93:149-156, 1993.

$\left[\mathrm{VCC}^{+} 96\right]$ B. Vieille, C. Chauveau, X. Chesneau, A. Odeide, and I. Gökalp. Highpressure droplet burning experiments in microgravity. Proceedings of the Combustion Institute, 26:1259-1265, 1996.

[VK67] D.S. Viswanath and N.R. Kuloor. On a generalized watson's relation for latent heat of vaporization. The Canadian Journal of Chemical Engineering, 45:29-31, 1967.

[WEP76] W. Wagner, J. Ewers, and W. Pentermann. New vapour-pressure measurements and a new rational vapour-pressure equation for oxygen. The Journal of Chemical Thermodynamics, 8:1049-1060, 1976. 
[WLY97] S.-C. Wong, X.-X. Liao, and J.-R. Yang. A simplified theory of the ignition of single droplets under forced convection. Combustion and Flame, 110:319-334, 1997.

[WMD01] J. Warnatz, U. Maas, and R.W. Dibble. Combustion. Springer, Berlin, 3 edition, 2001.

[WYHW97] J.-J. Whang, C.-Y. Yukao, J.-T. Ho, and S.-C. Wong. Experimental study of the ignition of single droplets under forced convection. Combustion and Flame, 110:366-376, 1997.

[YYWW00] J.-R. Yang, C.-Y. Yukao, J.-J. Whang, and S.-C. Wong. Experiments on the ignition of monocomponent and bicomponent fuel droplets in convective flow. Combustion and Flame, 123:266-274, 2000. 